\title{
Non-uniform temperature gradients and thermal stresses produced by a moving heat flux applied on a hollow sphere
}

\author{
HÜSEYIN YAPICI*, GÜLŞAH ÖZIŞIK and M SERDAR GENÇ
}

Erciyes Üniversitesi Mühendislik Fakültesi, 38039 Kayseri, Turkey

e-mail: yapici@erciyes.edu.tr

MS received 24 July 2008; revised 19 July 2009; accepted 11 January 2010

\begin{abstract}
This work presents numerical analyses of transient temperature and thermally-induced stress distributions in a hollow steel sphere heated by a moving uniform heat source applied on a certain zenithal segment (the heated zenithal segment, $\Theta_{H}$ ) of its outer surface (the processed surface) under stagnant ambient conditions. Along the process, the moving heat source (MHS) moves angularly from the first zenithal segment to the last zenithal segment on the processed surface with a constant angular speed, $\omega$, and then returns backward to the first zenithal segment with the same speed. It is assumed that the inner surface is heat-isolated and that the outer surface except the heated segment is under stagnant ambient conditions. The numerical calculations are performed individually for a wide range of thermal conductivity, $\lambda$, of steel and for the different $\Theta_{H} \mathrm{~s}$. The maximum effective thermal stress ratio calculated as per the heat flux intensity $\left(q_{0}\right)$ can be reduced in considerable amounts. By increasing $\lambda(\sim 75 \%)$ and $\omega(\sim 63 \%)$ the maximum effective thermal stress ratio calculated can be significantly reduced.
\end{abstract}

Keywords. Moving heat source; heat transfer; temperature distribution; thermal stress.

\section{Introduction}

The increase of temperature generated by frictional heat can involve mechanical microdeformations and an overheating of the cooling fluid. It is therefore important to have calculation models to evaluate temperatures according to the frictional heat generation, to which solids are subjected. Moreover, heat transfer due to a moving heat source (MHS) plays an important part in many manufacturing processes such as grinding, hardening, cutting, coating, metal forming, etc. MHS analyses enable a detailed characterization of temperatures produced during these processes. Therefore, an efficient finite element procedure has been developed to calculate temperatures and stresses arising from MHS by researchers during the last decade (Sunar et al 2006, Li \& Li 2005). The procedure is applied to calculate the thermal stresses produced in hardened steels during manufacturing. Furthermore, thermally-induced stresses are considered an important phenomena in many manufacturing processes and design applications.

*For correspondence 
Because, non-uniform heating or cooling of a uniform material or uniform heating of nonuniform materials causes thermal stress that is proportional to the temperature differential and the coefficient of thermal expansion of the material. And also, changes in temperature cause thermal effects on a solid work piece during the cooling and heating processes. Some of these thermal effects include thermal stress, strain and deformation.

The calculations of temperature distribution and thermal stress have been of great scientific interest recently. Eslam et al (2005) have presented a general solution for the one-dimensional steady-state thermal and mechanical stresses in a hollow thick sphere made of functionally graded. In this study, the temperature distribution is assumed to be a function of radius, with general thermal and mechanical boundary conditions on the inside and outside surfaces of the sphere. Bairi et al (2004) studied the temperature distribution in a bearing ball subjected to elliptic MHSs and surface cooling is presented in this study. They have presented an analytical solution in order to determine the thermal behaviour of a bearing ball subjected to uniform or parabolic heat source, on an elliptic region. Laraqi et al (2004) have developed analytical solutions to calculate the three-dimensional temperature distribution and the thermal constriction resistance due to the MHSs on semi-infinite bodies. By varying the values of geometric parameters in the provided solutions, they get the solution for various cases like unique or multiple: strip, rectangular, square, elliptic and circular MHSs. Sunar et al (2006) considered a cantilever assembly subjected to heating at its fixed end, which resembles the welding of a sheet metal. Temperature and stress fields were computed during the heating process. A control volume approach was introduced for the numerical solution of heat transfer equations while the finite element method was adopted for stress field predictions. They found that the temperature distribution in the transverse direction does not vary considerably, but varies significantly in the longitudinal direction. The temporal change of temperature gradient induces stresses in the substrate material. However, the maximum magnitude of the Von-Mises stress is less than the yield strength of the substrate material. Al-Huniti et al (2001) investigated the dynamic thermal and elastic behaviour of a rod due to a MHS. They used an analytical-numerical technique based on the Laplace transformation and the Riemannsum approximation to calculate the temperature, displacement and stress distributions in the rod. Moulik et al (2001) calculated transient stresses and temperatures in an elastic solid and found to be in good agreement with prior analytical and numerical results. They obtained that the calculated transient stresses and temperatures in an elastic solid are found to be in good agreement with prior analytical and numerical results. Li \& Li (2005) investigated both analytically and numerically the temperature distribution in workpiece during scratching and grinding. They used the finite element method to simulate the transient heat transfer process of a MHS along the surface of a half space and found that for the same heat source, the shape of temperature contour over the contact interface is not sensitive to the convection coefficient of the environment. There are some restrictions in the prediction of location and strength problems in recent studies. One of the restrictions is that there is no method available to estimate the location and the strength of two moving sources presently. Yang (2006) proposed a numerical algorithm to determine the problem sequentially. The results of this study show that the proposed method is an accurate and efficient method to determine the position and the strength of two moving sources in the inverse heat conduction problem. Yilbas et al (2002) also considered laser pulse heating of a steel surface and flexural wave analysis. In this study, the generated flexural wave is simulated, and the wave characteristics are analysed at four locations at the work piece surface. Al-Zaharnah et al (2000, 2001a and 2001b) analysed conjugate heat transfer in fully developed laminar pipe flow and the thermally-induced stresses. This study showed that the low Prandtl number and low thermal conductivity ratios result 
in almost uniform radial temperatures and low radial effective stresses. They also analysed thermal stresses in thick walled pipes subjected to fully developed laminar flow and pulsating flow, respectively. These studies show that the wall thickness and pipe diameter are significant parameters affecting the resulting stress distribution. Kim et al (2000) have investigated analysis of the thermal stress evolution in the steam drum during start up of a heat recovery steam generator. In this study, it is shown that bypassing part of the gas flow lowers the peak stress much in the case of steady gas turbine exhaust condition.

In previous works, the temperature and thermally-induced stress distributions in externally heated circular pipe (Yapıc1 \& Albayrak 2004a and Yapıc1 et al 2005) and heated cylindrical workpiece (Yapıc1 \& Yalcın 2004; Yapıcı \& Bastürk 2005a) were analysed numerically by using a CFD computer code, respectively. Furthermore, the numerical solutions of transient temperature and thermally-induced stress distributions in a solid disk heated with radially periodic expanding and contracting ring heat flux in one side surface were studied (Yapic1 \& Baştürk 2005b and 2006). The later studies (Yapıcı et al 2008; Özısık et al 2008 and Genç et al 2009) presented the thermally-induced stress and temperature distributions in a stationary hollow disk, in a steel plate partially heated by a moving uniform heat source from its outer surface under stagnant ambient conditions and in a rotating hollow disk heated from one side surface. Our earlier studies (Yapıc1 \& Albayrak 2004; Yapıc1 \& Yalcın 2004; Yapıc1 et al 2005; Yapıc1 \& Bastürk 2005a, 2005b and 2006) do not include MHS, the later studies (Yapic1 et al 2008; Özısık et al 2008 and Genç et al 2009) and this study point out the importance of the MHS in a workpiece. This work presents the thermally-induced stress and temperature distributions in a hollow spherical workpiece heated partly-circumferentially from its outer surface by a moving uniform heat source.

\section{Mathematical modelling}

For this study, a hollow steel sphere (workpiece) heated partly-circumferentially from its outer surface (processed surface) by a moving uniform heat source under stagnant ambient conditions is considered to analyse numerically the transient temperature distributions. As already known, heat is released in a solid subjected to manufacturing processes such as grinding, hardening, cutting, coating, metal forming, etc. Temperature difference, occurring in this solid because of non-uniformities of the released heat, cooling and/or thermal properties of the solid material, may cause thermal stress. This study presents also the thermally-induced stress that is proportional to the temperature differential. Axisymmetric geometric model of the considered sphere and the coordinate system are shown in figure 1. The processed surface

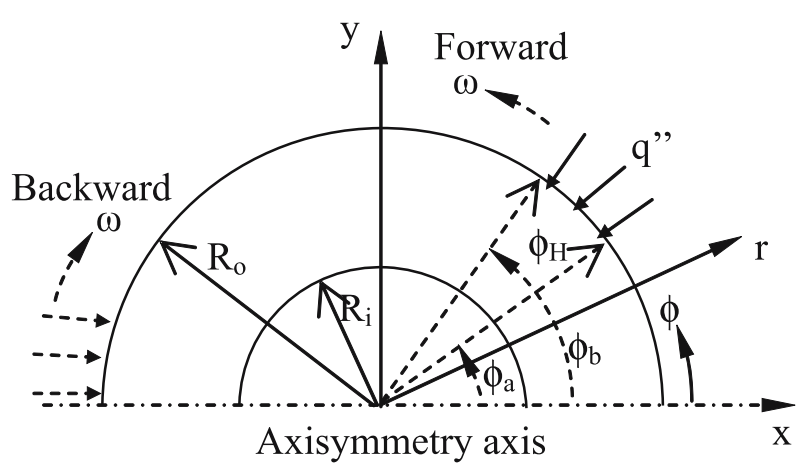

Figure 1. Axisymmetric geometric model of the considered sphere (dimensions are not in scale). 


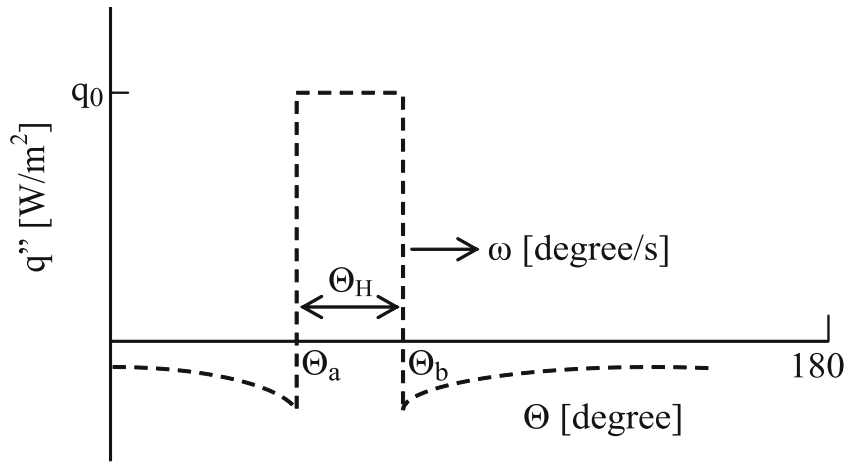

Figure 2. The moving heat flux profile applied on the processed surface of the sphere, (the profile is not in scale).

is divided artificially into 180 equal angular (zenithal) segments ( $\Theta s$ in degree) in zenithal direction $(\phi)$, and when these segments are not exposed to the heat flux, they are under stagnant ambient conditions (see figure 2). It is assumed that the inner surface is heat-isolated and that the MHS is uniform along the azimuthal direction $(\theta)$. Along the process, this flux moves from the first zenithal segment to the last zenithal segment on the processed surface with a constant angular speed, $\omega$, and then returns backward to the first zenithal segment with the same speed, $\omega$. This motion produces the non-uniform temperature gradients in the sphere, which in turn causes the non-uniform and unsteady thermal stresses.

From the above explanations, three situations are considered; (i) heat conduction inside the sphere, (ii) heat convection from the sphere surface to the surrounding, and (iii) thermallyinduced stress in the sphere. The governing equations for the analyses of these situations are as follows:

\subsection{The governing heat conduction equation}

The following important assumptions are made in the present analysis:

- The thermo-physical property variations of the workpiece are negligible.

- The workpiece material is homogeneous and isotropic.

- The heat flux per unit area is uniform along the azimuthal direction.

- The temperature, $T$, depends on $r, \phi$ and $t,(T=T(r, \phi, t))$.

In the hollow sphere (inner radius, $R_{i}, \leq r \leq$ outer radius, $R_{o}$, and $0 \leq \phi \leq 2 \pi$ ),

$$
\frac{\partial^{2} T}{\partial r^{2}}+\frac{2}{r} \frac{\partial T}{\partial r}+\frac{\cos (\phi)}{r^{2} \sin (\phi)} \frac{\partial T}{\partial \phi}+\frac{1}{r^{2}} \frac{\partial^{2} T}{\partial^{2} \phi}=\frac{\rho \cdot C_{p}}{\lambda} \frac{\partial T}{\partial t} .
$$

\subsection{Initial and boundary conditions}

At $t=0, T(r, \phi, 0)=T_{\text {amb }}$.

At the inner surface $\left(r=R_{i}\right), \frac{\partial T\left(R_{i}, \phi, t\right)}{\partial r}=0$.

At the outer surface $\left(r=R_{o}\right), \lambda \frac{\partial T\left(R_{o}, \phi, t\right)}{\partial r}=q^{\prime \prime}(T, \phi, t)$. 

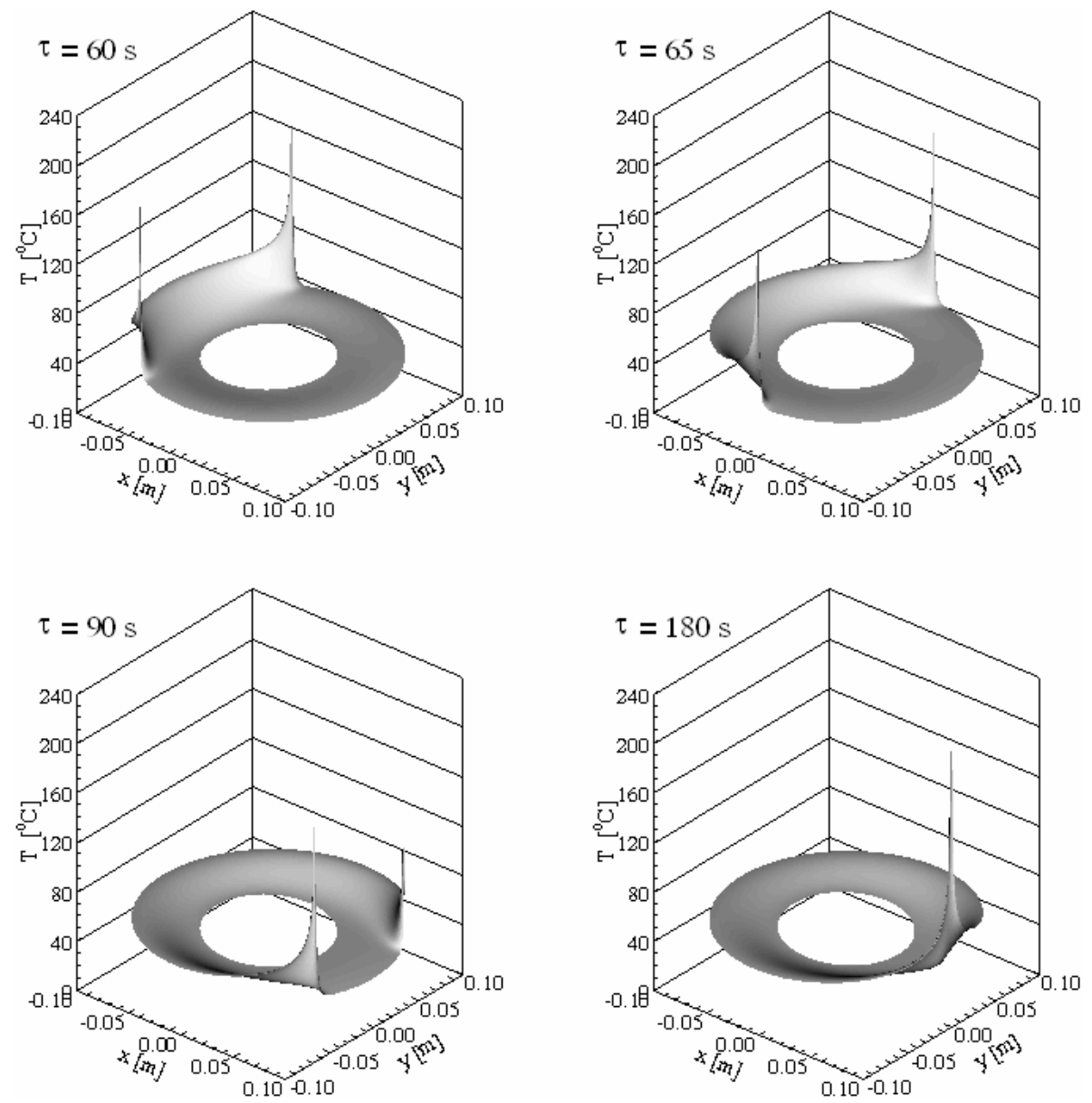

Figure 3. Temperature distributions in the midplane of the hollow sphere within the sixth cycle, $t=900+\tau \mathrm{s},\left(\lambda=10 \mathrm{~W} / \mathrm{m}-\mathrm{K}, \Theta_{H}=1\right.$ degree and $\left.P=180 \mathrm{~s}\right)$.

where $\lambda$ is the thermal conductivity, $h$ is the heat transfer coefficient, $q^{\prime \prime}(T, \phi, t)$ is a moving heat flux function in the zenithal direction, and for this study, it is assumed as follows:

$$
q^{\prime \prime}(T, \phi, t)=q_{h}^{\prime \prime}(\phi)+q_{c}^{\prime \prime}(T, \phi, t),
$$

where $q_{h}^{\prime \prime}$ and $q_{c}^{\prime \prime}$ are the heat fluxes per unit area applied on the heated zenithal segment, and transferred from the processed surface to the surrounding, respectively, and defined as follows:

$$
\begin{aligned}
& q_{h}^{\prime \prime}(\phi)=q_{0} \cdot\left[\Phi\left(\phi_{b}-\phi\right)-\Phi\left(\phi_{a}-\phi\right)\right] \\
& q_{c}^{\prime \prime}(T, \phi, t)=-h_{\mathrm{amb}} \cdot\left(T\left(R_{o}, \phi, t\right)-T_{\mathrm{amb}}\right) \cdot\left[1-\left[\Phi\left(\phi_{b}-\phi\right)-\Phi\left(\phi_{a}-\phi\right)\right]\right],
\end{aligned}
$$



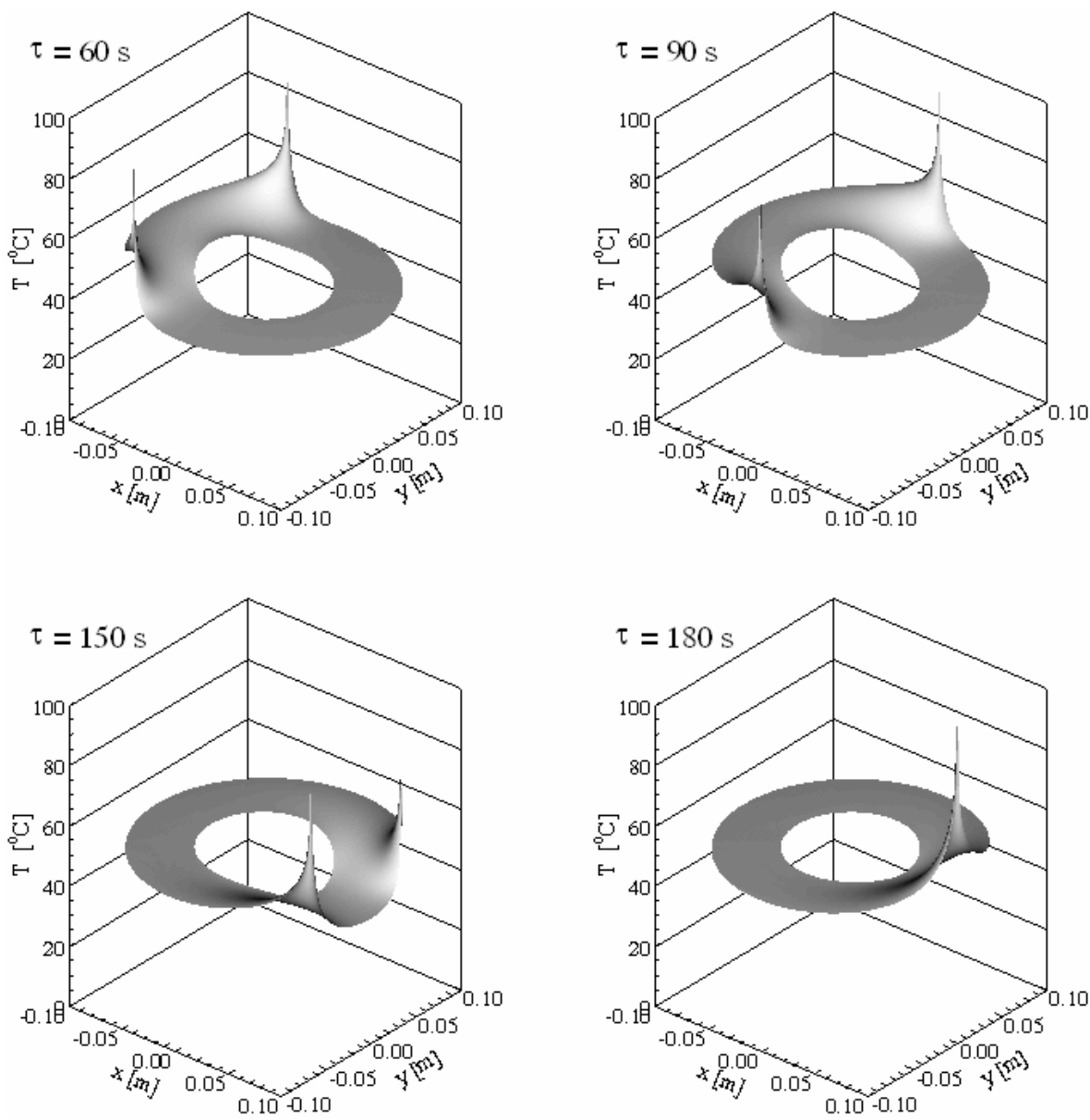

Figure 4. Temperature distributions in the midplane of the hollow disk within the sixth cycle, $t=900+\tau \mathrm{s},\left(\lambda=50 \mathrm{~W} / \mathrm{m}-\mathrm{K}, \Theta_{H}=1\right.$ degree and $\left.P=180 \mathrm{~s}\right)$.

where $q_{0}$ is intensity of the moving heat flux per unit area, and $\Phi$ is Heaviside step function and defined as follows:

$$
\Phi\left(x-x_{0}\right)=\left\{\begin{array}{lll}
0 & \text { if } \quad x<x_{0} \\
1 & \text { if } \quad x \geq x_{0}
\end{array} .\right.
$$

The heat transfer rate $(Q)$ varies proportionally with the heated area $\left(A_{H}\right)$ that depends on $\theta_{H}$, and is calculated as follows:

$$
\begin{aligned}
& Q=q_{0} \cdot A_{H} \\
& A_{H}=2 \cdot \pi \cdot R_{o}^{2} \cdot\left|\left[\cos \left(\phi_{a}\right)-\cos \left(\phi_{b}\right)\right]\right| \\
& \phi=\Theta \cdot \pi / 180 \\
& \Theta_{H}=\Theta_{b}-\Theta_{a}
\end{aligned}
$$



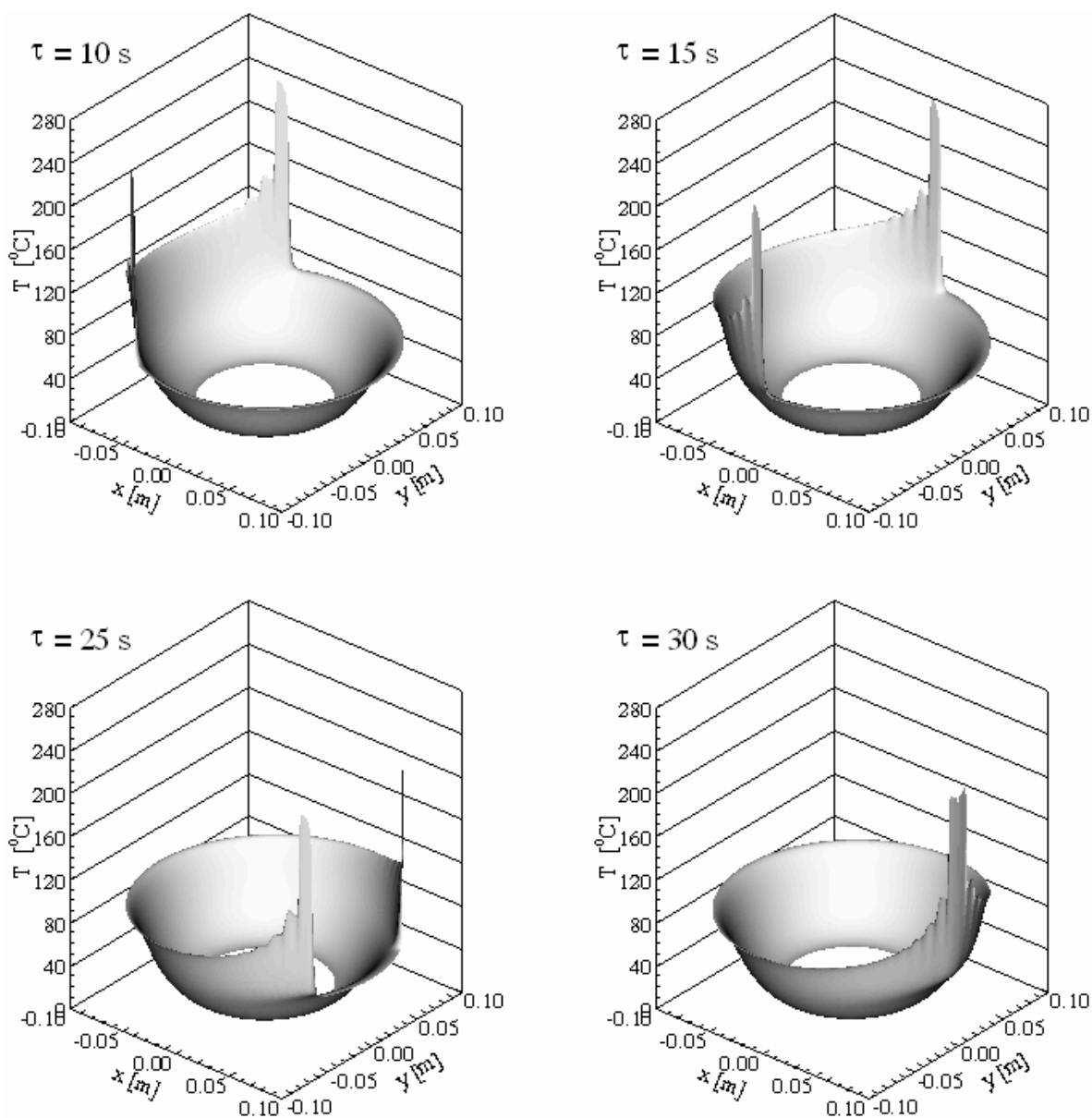

Figure 5. Temperature distributions in the midplane of the hollow disk within the sixth cycle, $t=150+\tau \mathrm{s},\left(\lambda=10 \mathrm{~W} / \mathrm{m}-\mathrm{K}, \Theta_{H}=6\right.$ degree and $\left.P=30 \mathrm{~s}\right)$.

$$
\begin{aligned}
& \Theta_{a}= \begin{cases}0 & \text { if } 0<\tau \leq 1 \\
(\tau-1) \cdot \omega+1 & \text { otherwise }\end{cases} \\
& \Theta_{b}=\tau \cdot \omega \\
& \tau= \begin{cases}t-(j-1) \cdot P & j=1,3, \ldots, n-1 \\
j \cdot P-t+1 & j=2,4, \ldots, n\end{cases} \\
& P=180 / \omega,
\end{aligned}
$$

where $\tau$ is the normalized time, $j$ represents the $j$-th cycle, and $P$ is the time for one cycle, and $n$ is total cycle number.

The calculations are performed only for the zenith angular interval $0 \leq \phi \leq \pi$, due to the fact that the considered sphere is symmetric about the axisymmetry axis (figure 1). 

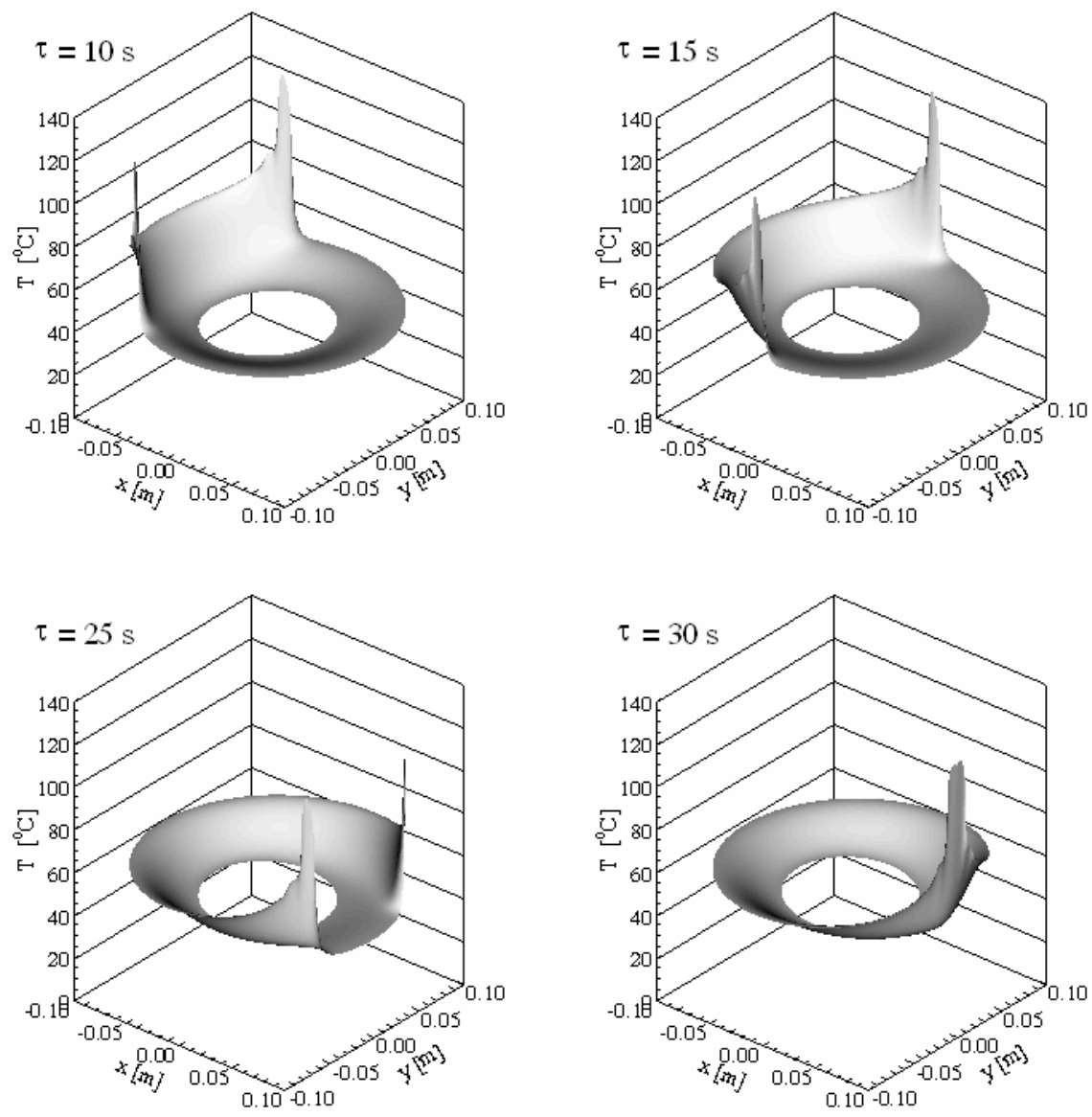

Figure 6. Temperature distributions in the midplane of the hollow disk within the sixth cycle, $t=150+\tau \mathrm{s},\left(\lambda=50 \mathrm{~W} / \mathrm{m}-\mathrm{K}, \Theta_{H}=6\right.$ degree and $\left.P=30 \mathrm{~s}\right)$.

\subsection{The governing thermal stress equations (Fauple \& Fisher 1981)}

To obtain the thermal stress distribution, it is assumed that the hollow sphere reaches thermal equilibrium at the end of each time interval. Therefore, two thermal stress components in tangential $(t)$ and radial $(r)$ directions are calculated at each time interval. The general thermal stress equations are given as follows:

$$
\begin{aligned}
& \text { for hollow sphere }\left(R_{i} \leq r \leq R_{o}\right) \text { : } \\
& \begin{aligned}
\sigma_{t}= & \frac{2 \cdot E \cdot \alpha}{(1-v) \cdot r^{3}} \cdot\left[\frac{2 \cdot r^{3}+R_{i}^{3}}{2 \cdot\left(R_{o}^{3}-R_{i}^{3}\right)} \cdot \int_{R_{i}}^{R_{o}} T(r) \cdot r^{2} \cdot d r\right. \\
& \left.\quad+\frac{1}{2} \cdot \int_{R_{i}}^{r} T(r) \cdot r^{2} \cdot d r-\frac{1}{2} \cdot T(r) \cdot r^{3}\right] . \\
\sigma_{r}= & \frac{2 \cdot E \cdot \alpha}{(1-v) \cdot r^{3}} \cdot\left[\frac{r^{3}-R_{i}^{3}}{R_{o}^{3}-R_{i}^{3}} \cdot \int_{R_{i}}^{R_{o}} T(r) \cdot r^{2} \cdot d r-\int_{R_{i}}^{r} T(r) \cdot r^{2} \cdot d r\right] .
\end{aligned}
\end{aligned}
$$


The effective stress according to Von-Mises theory (Fauple \& Fisher 1981) is given by

$$
\sigma_{\mathrm{eff}}(r)=\sqrt{\left[\sigma_{t}(r)\right]^{2}+\left[\sigma_{r}(r)\right]^{2}-\sigma_{t}(r) \cdot \sigma_{r}(r)} .
$$

In order to obtain the thermal stress distributions independently of the physical properties $(E, \alpha$ and $v$ ) of the material, the thermal stress ratio, $\sigma *(r)$, can be expressed as follows:

$$
\sigma^{*}(r)=\frac{\sigma(r)}{\frac{E \cdot \alpha}{1-\nu}} .
$$

\section{Numerical results}

\subsection{Calculational tools and procedure}

The transient heat conduction eq. (1) along with the initial and boundary condition eqs. (2a-f) can be solved numerically by a suitable computer code using finite difference method. For this analysis, the FLUENT $6 \cdot 1$ program (Fluent Inc. 2003) is chosen as the computer code because of the ease with which the analysis model can be created and the software allows users to modify the code for special analysis conditions through the use of user subroutines. The FLUENT computer code uses a finite-volume procedure to solve the conduction heat transfer within solids. The boundary conditions eq. (2c) with eqs. $(2 d-f)$ show that the heat source moves angularly in the zenithal direction (independent of $\theta$ ) on the processed surface depending on the process time. Therefore, an interpreted UDF (User Defined Function) file is prepared for simulating this moving heating process, and it is introduced to the prepared FLUENT case file as an outer surface boundary condition. The UDF files can provide

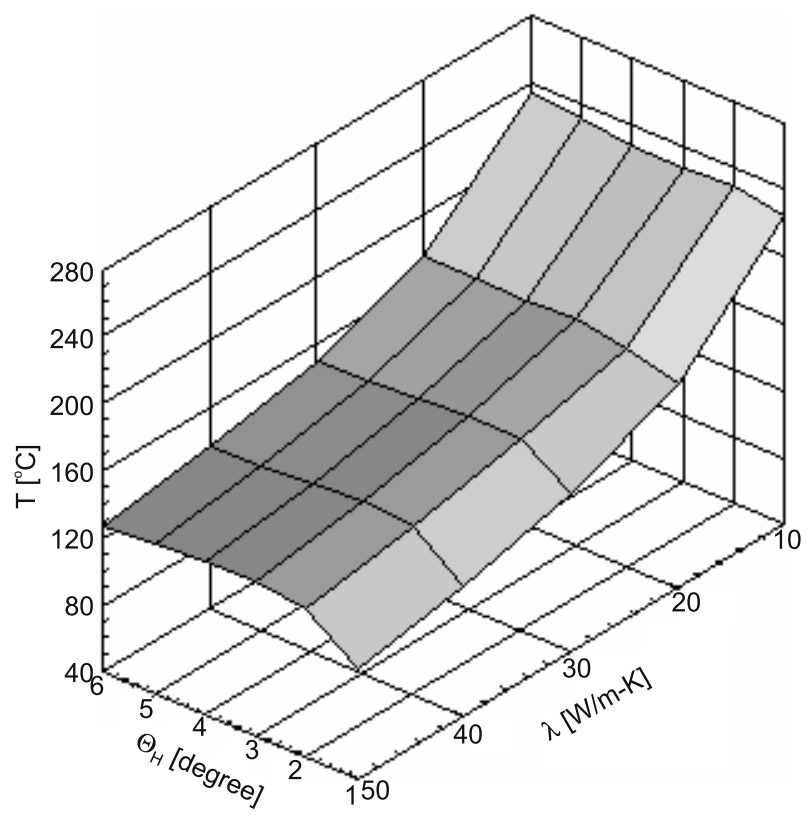

Figure 7. Variation of the maximum temperature in the hollow sphere at the end of sixth cycle with $\lambda$ and $\Theta_{H}$. 

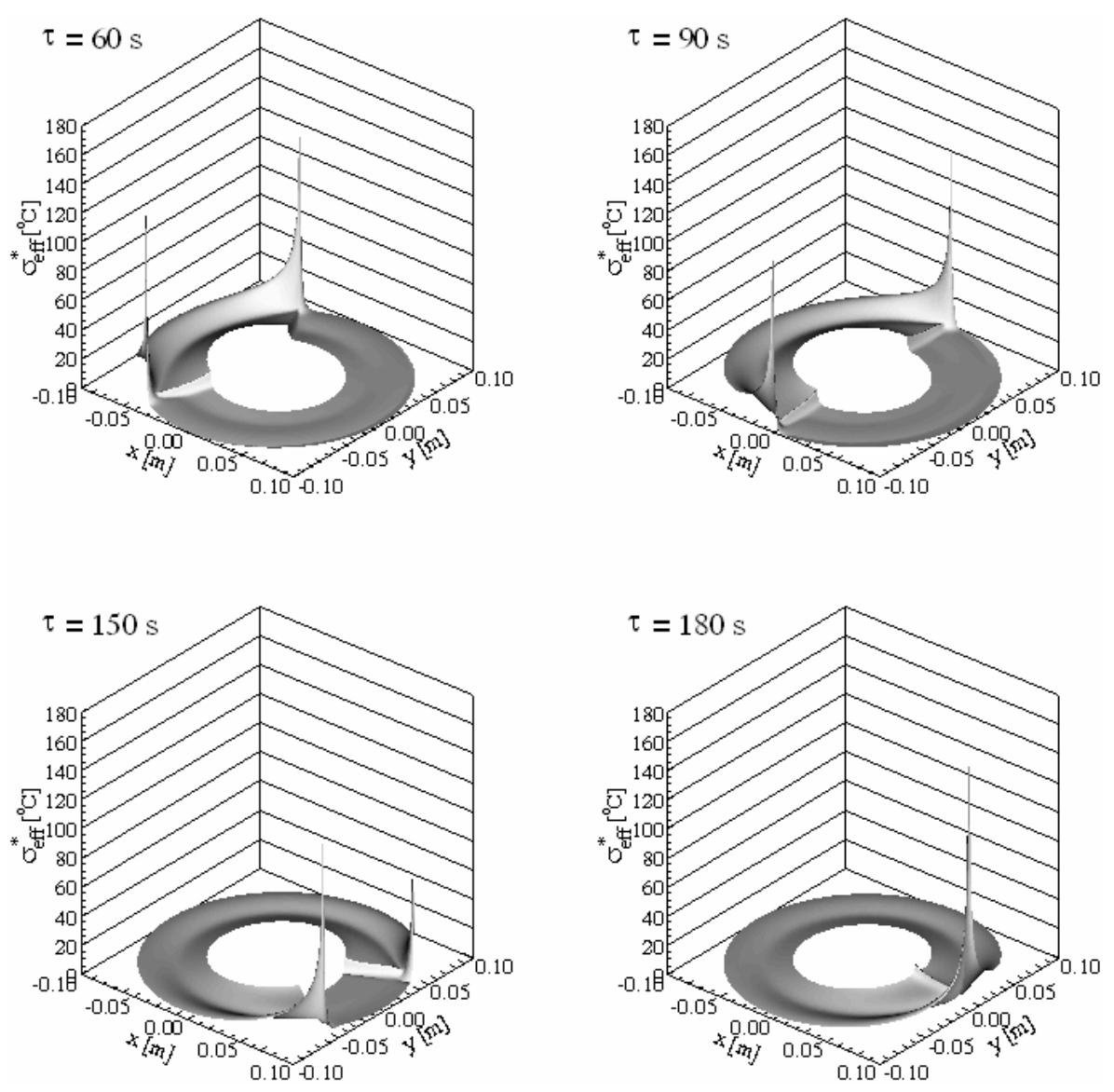

Figure 8. Effective thermal stress ratio distributions in the midplane of the hollow sphere within the sixth cycle, $t=900+\tau \mathrm{s},\left(\lambda=10 \mathrm{~W} / \mathrm{m}-\mathrm{K}, \Theta_{H}=1\right.$ degree and $\left.P=180\right)$.

the capability to customize boundary conditions source terms, property definitions (except specific heat), surface and volume reaction rates, user-defined scalar transport equations, discrete phase model (e.g. body force, drag, source terms), algebraic slip mixture model (slip velocity and particle size), solution initialization, wall heat fluxes, and post-processing using user-defined scalars, and so they can significantly enhance the capability of FLUENT. There are two types of user-defined functions: interpreted and compiled. Interpreted UDF file can be compiled at runtime within a FLUENT session. Moreover, the heat conduction calculation results obtained with the help of the FLUENT code are verified by using the HEATING7 (Childs et al 1990) computer code. In addition to these two codes and the written UDF file, a computer program, applying the numerical integration method to the obtained temperature distributions from the heat transfer calculations, has been developed to calculate numerically the thermal stress distributions defined with eqs. $(5 \mathrm{a}-\mathrm{c})$.

The numerical calculations are performed individually for a wide range of $\lambda$ of steel (from 10 to $50 \mathrm{~W} / \mathrm{m}-\mathrm{K}$ stepped by $10 \mathrm{~W} / \mathrm{m}-\mathrm{K}$ ), and for the different $\Theta_{H} \mathrm{~s}$ (from 1 to 6 degrees increased by 1 degree) under transient conditions. Due to the axisymmetricity of the hollow sphere (figure 1), the highest temperature differences, inducing the thermal stress, take place 

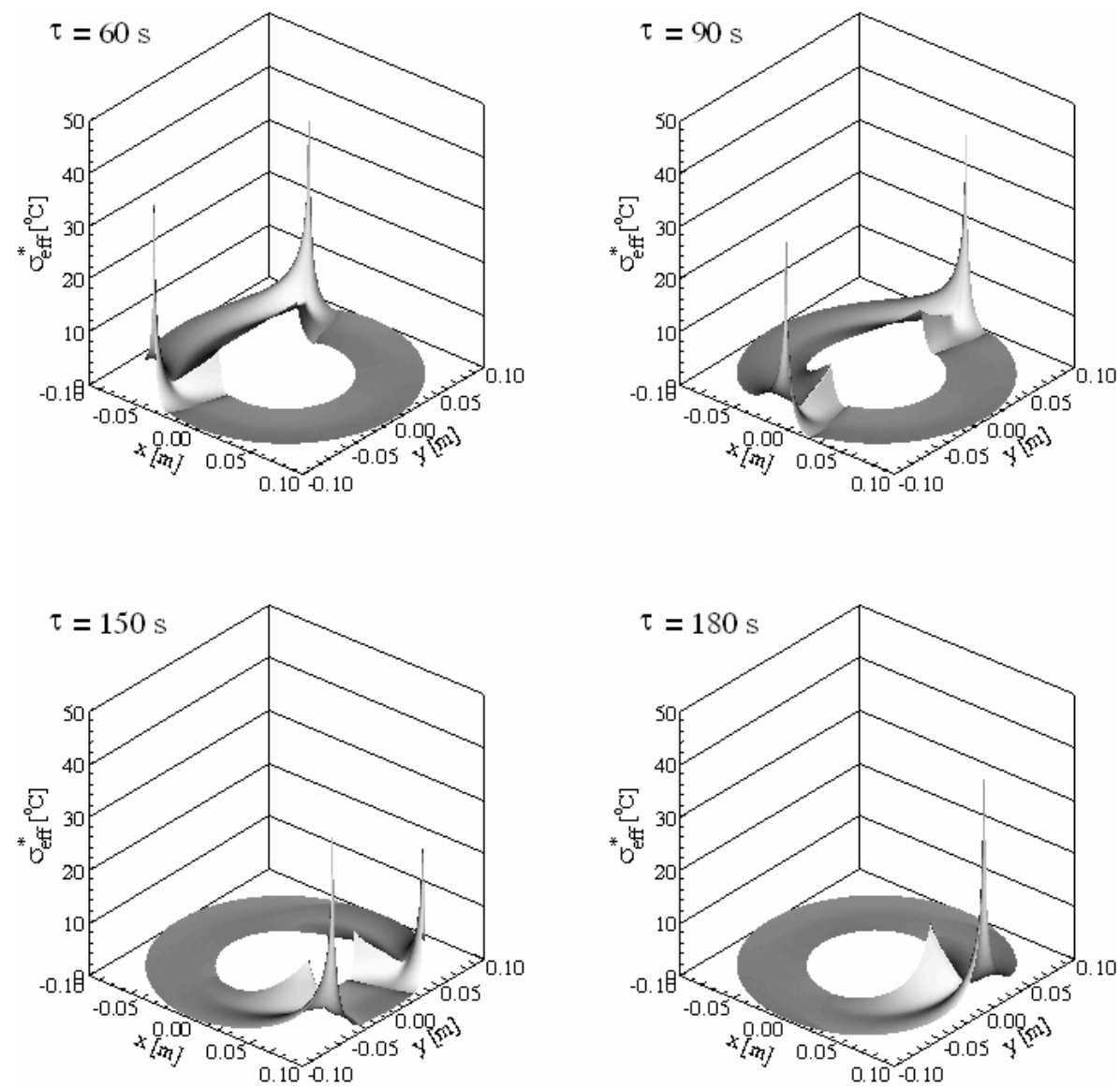

Figure 9. Effective thermal stress ratio distributions in the midplane of the hollow sphere within the sixth cycle, $t=900+\tau \mathrm{s},\left(\lambda=50 \mathrm{~W} / \mathrm{m}-\mathrm{K}, \Theta_{H}=1\right.$ degree and $\left.P=180\right)$.

in the $z=0, x-y$ plane that is the midplane of the sphere. Therefore, in this study, the temperature and thermal stress ratio distributions only in this plane are presented.

\subsection{Simulation parameters}

$R_{i}=0.05 \mathrm{~m}, R_{o}=0.1 \mathrm{~m}, q_{0}=10^{6} \mathrm{~W} / \mathrm{m}^{2}, h_{\mathrm{amb}}=20 \mathrm{~W} / \mathrm{m}^{2}-\mathrm{K}, T_{\mathrm{amb}}=0^{\circ} \mathrm{C}$, for steel, $\rho=$ $7800 \mathrm{~kg} / \mathrm{m}^{3}, C_{P}=470 \mathrm{~J} / \mathrm{kg}-\mathrm{K}$ and $\lambda=10,20, \ldots, 50 \mathrm{~W} / \mathrm{m}-\mathrm{K}, \omega=1,2, \ldots, 6$ degrees $/ \mathrm{s}$, (which corresponds to $\Theta_{H}=1,2, \ldots 6$ degrees), $t=0$ to $180 \cdot n / \omega \mathrm{s}$ stepped by $1 / \omega \mathrm{s}, n=6$ cycles, $x=r \cdot \cos (\phi)$ and $y=r \cdot \sin (\phi)$.

3.2a Grid size: The grid independent tests are carried out to ensure grid independence of the calculated results. The grid size and the grid orientation giving the grid independent results are selected, and thus the total cell number of 144000 cells $(100 \times 1440$ in the $r$ and $\phi$ directions, respectively) are adopted.

In order to obtain the temperature difference per $q_{0}$, it is assumed that the thermal properties of the sphere do not change with temperature. The thermal stress distributions also will be per $q_{0}$ due to the fact that they are proportional to the temperature differences (see eqs. $(5 \mathrm{a}, \mathrm{b})$ ). 

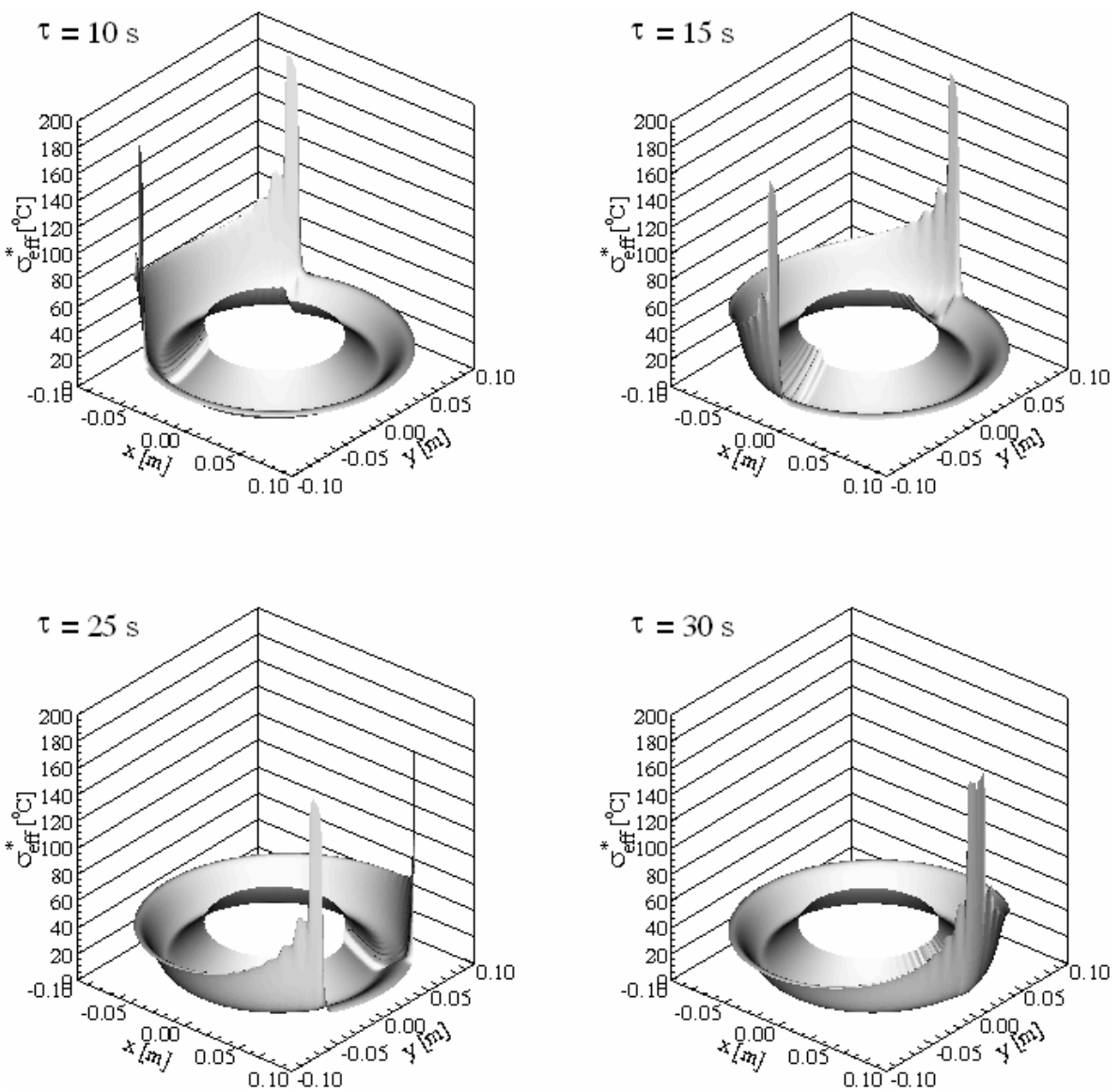

Figure 10. Effective thermal stress ratio distributions in the midplane of the hollow sphere within the sixth cycle, $t=150+\tau \mathrm{s},\left(\lambda=10 \mathrm{~W} / \mathrm{m}-\mathrm{K}, \Theta_{H}=6\right.$ degrees and $\left.P=30 \mathrm{~s}\right)$.

\subsection{Temperature distributions}

The temperature distributions and their steep gradients in the midplane of the considered sphere at the different times (normalized times) of the sixth cycle are plotted in figures 3-6 for $\lambda=10$ and $50 \mathrm{~W} / \mathrm{m}-\mathrm{K}$ in the cases of $\Theta_{H}=1$ and 6 degrees, respectively. The four different normalized times in the each figure correspond to $\Theta_{b}=60,90,150$ and 180 degrees, respectively.

The MHS applied on the outer surface of the sphere causes the non-uniform temperature gradients that are steep within and near the region of moving source because it is brought into focus on a quite small section of this surface and the heated segment is exposed to the stagnant ambient condition after the MHS leaves this segment. The peaks of these profiles relocate angularly in the zenithal direction depending on the motion of the MHS. Furthermore, the sections swept by the heat source and including the high temperature profiles widen in the sweep direction. However, the levels of the temperature at the faraway sections from the heat source are quite lower than those near the MHS. The numerical results bring out that in all cases of $\Theta_{H}$, the grades of the steep temperature gradient rise very little after four- 

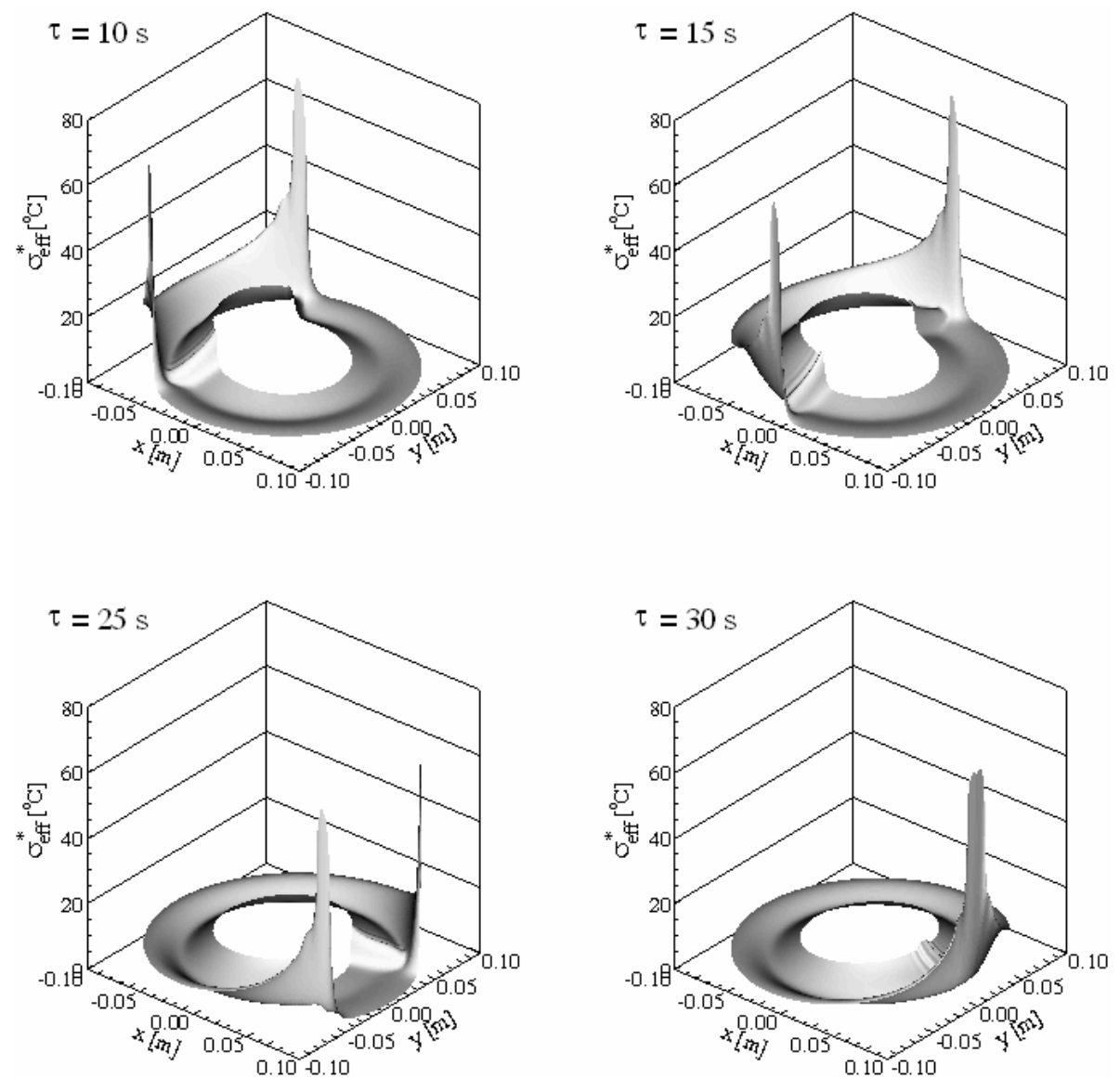

Figure 11. Effective thermal stress ratio distributions in the midplane of the hollow sphere within the sixth cycle, $t=150+\tau \mathrm{s},\left(\lambda=50 \mathrm{~W} / \mathrm{m}-\mathrm{K}, \Theta_{H}=6\right.$ degrees and $\left.P=30 \mathrm{~s}\right)$.

five cycles. However, when $\Theta_{H}$ is expanded, this grade rises on account of the increase of the heat transfer rate penetrating into the sphere and the field widens in which the high and non-uniform temperature gradients occur.

In heating process, it is crucial to know the highest temperature of the processed object to carry out the work safely. Therefore, the maximum temperature grades are determined for all cases and their variation at the end of sixth cycle with $\lambda$ and $\Theta_{H}$ is plotted in figure 7 as the meshed graphic. As expected, the maximum temperature grade decreases in a considerable amount (approximate in the ratio of $1 / 2$ ) with the increase of $\lambda$, from 10 to $50 \mathrm{~W} / \mathrm{m}-\mathrm{K}$, because the temperature gradient is inversly proportional to $\lambda$. These quasi-exponential (much more in the low $\lambda \mathrm{s}$ ) decreases are from 225 to $106^{\circ} \mathrm{C}$ and from 234 to $128^{\circ} \mathrm{C}$, in the cases of $\Theta_{H}=1$ and 6 degrees, respectively. It is also apparent from these values that as $\Theta_{H}$ is enlarged from 1 to 6 degrees, the maximum temperature increases quasi-logarithmically (approximate 1.04 and 1.2 times in the cases of $\lambda=10$ and $50 \mathrm{~W} / \mathrm{m}-\mathrm{K}$, respectively). Nevertheless, in the low $\lambda \mathrm{s}$, this increase is quite low, in other words, the expansion of $\Theta_{H}$ does not much influence the temperature levels. 

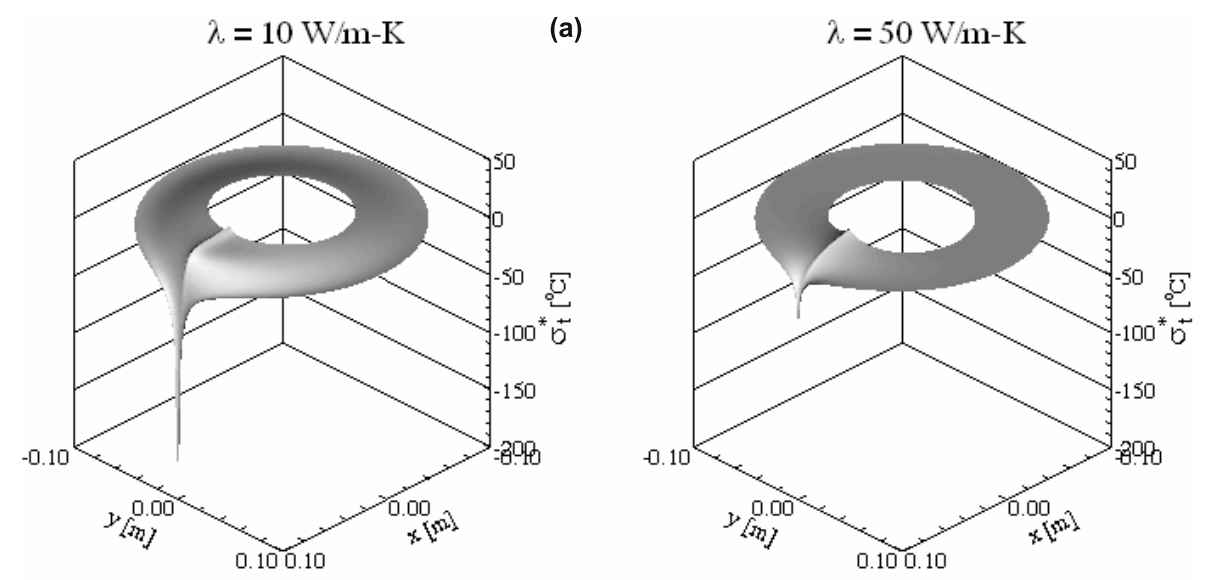

(b)
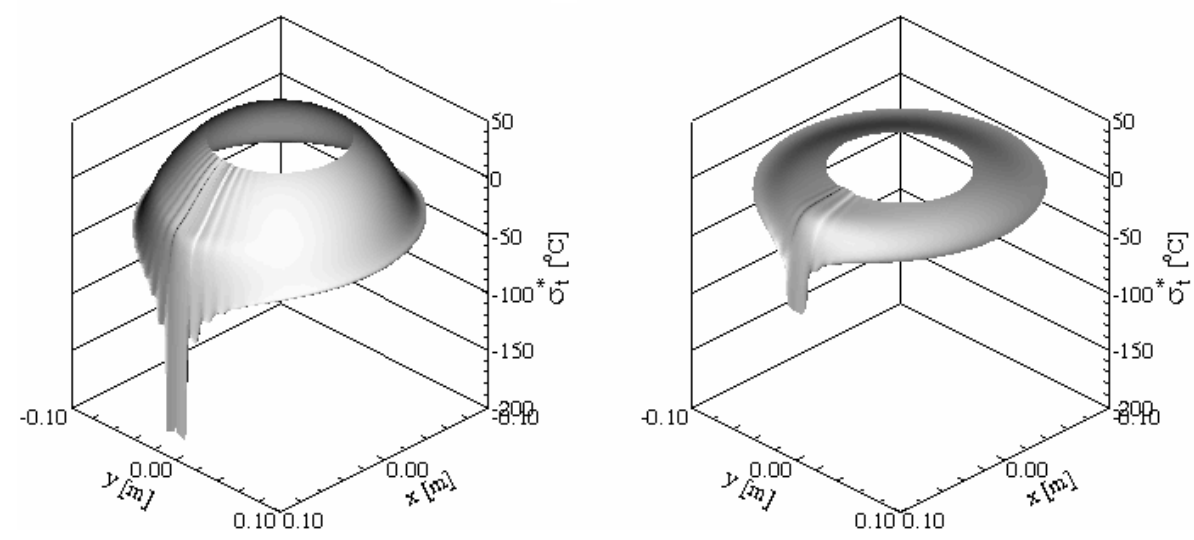

Figure 12. Tangential thermal stress ratio distributions in the midplane of the hollow sphere at the end of sixth cycle, (a) $\Theta_{H}=1$ and (b) $\Theta_{H}=6$ degrees.

\subsection{Thermal stress distributions}

The thermally-induced stresses calculated numerically with eqs. $(5 a-c)$ under the thermal equilibrium assumption mentioned in section 2 are plotted for the various cases of the $\Theta$ and $\lambda$ as the thermal stress ratio, $\sigma^{*}(r)$, defined with eq. (5d). Note that the thermal stresses are proportional to the temperature difference and per $q_{0}\left(1 \mathrm{MW} / \mathrm{m}^{2}\right)$.

The effective thermal stress ratio distributions induced by the temperature differences in the midplane of the considered sphere at the different normalized times of the sixth cycle are plotted in figures $8-11$ for $\lambda=10$ and $50 \mathrm{~W} / \mathrm{m}-\mathrm{K}$ in the cases of $\Theta_{H}=1$ and 6 degrees, respectively. The correspondents of the normalized times are same with those in section $3 \cdot 3$. The effective thermal stress ratio profiles also peak at the heated segment due to the steep temperature gradients (as temperature distribution profiles) figures 3-7. These peaks are nonuniform within and near the region of moving source, and this non-uniform region widens with the expansion of $\Theta_{H}$. Moreover, they relocate angularly in the zenithal direction depending on the motion of the MHS. At the faraway sections from the heat source, the thermal stress ratios are quite low and quasi-uniform at the temperature profiles. It is an expected 


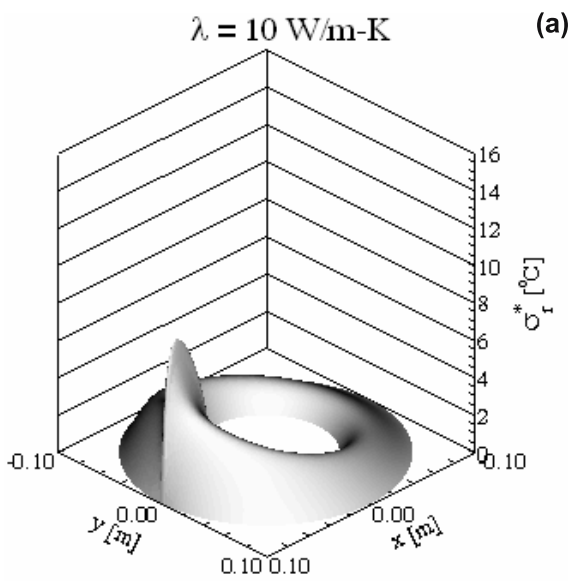

(a)

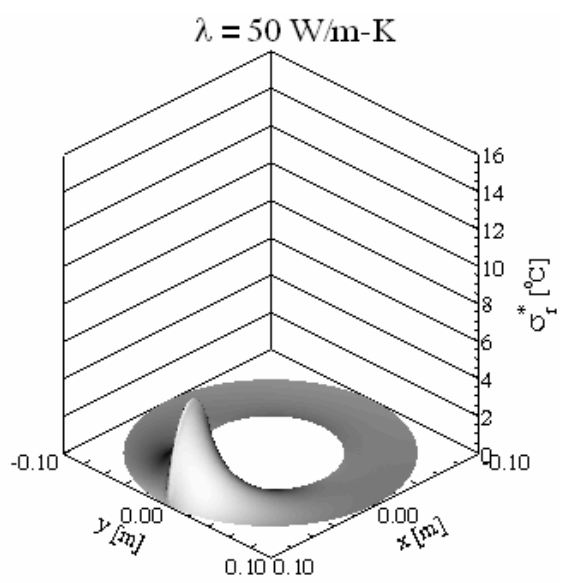

(b)
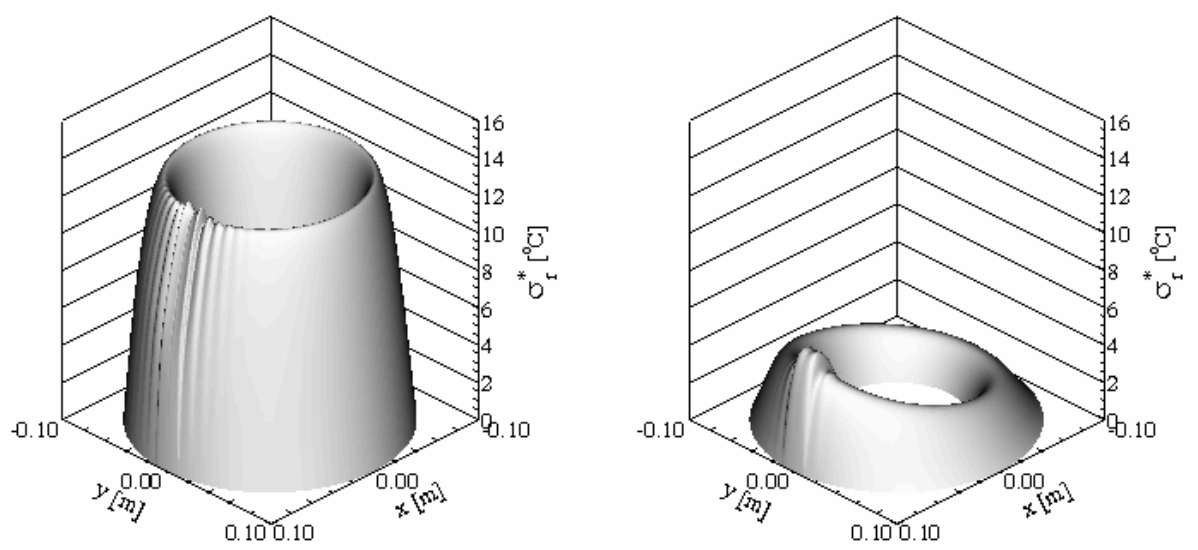

Figure 13. Radial thermal stress ratio distributions in the midplane of the hollow sphere at the end of sixth cycle, $\left[(\mathbf{a}) \Theta_{H}=1\right.$ and (b) $\Theta_{H}=6$ degrees $]$.

result that the thermal stress profiles show the same behaviour with the temperature profiles. On the other hand, for these $\lambda \mathrm{s}$ and $\Theta_{H} \mathrm{~s}$, figures 12 and 13 indicate the tangential and radial components of the thermal stress ratio in the midplane of the sphere at the end of sixth cycle, respectively. It is evident from these figures that the quantity (as absolute value) of the tangential component is quite high with respect to that of the radial component. This means that the tangential component is more dominant than the radial component in the effective thermal stress.

Figure 14 presents the variation of the maximum effective thermal stress ratio at the end of sixth cycle with $\lambda$ and $\Theta_{H}$ as the meshed graphic. Figures 14 and 7 demonstrate that the maximum effective thermal stress ratio profile shows similar behaviour with the maximum temperature profile. Depending on the variations of $\lambda$ and $\Theta_{H}$, the level of the maximum effective thermal stress ratio profile varies in the range of 44 to $180^{\circ} \mathrm{C}$. The expansion of $\Theta_{H}$ increases its level (only 1.08 and 1.6 times in the cases of $\lambda=10$ and $50 \mathrm{~W} / \mathrm{m}-\mathrm{K}$, respectively), whereas the increase of $\lambda$ (from 10 to $50 \mathrm{~W} / \mathrm{m}-\mathrm{K}$ ) reduces this level in considerable amounts (approximately $75 \%$ and $60 \%$ in the cases of $\Theta_{H}=1$ and 6 degrees, respectively). 


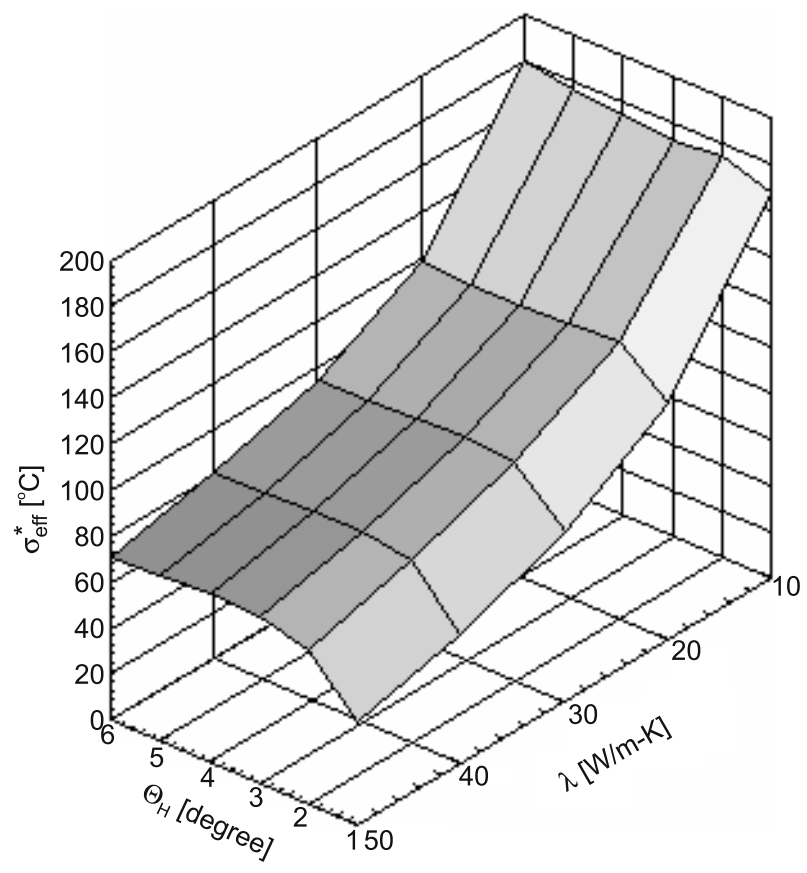

Figure 14. Variation of the maximum effective thermal stress ratio in the hollow sphere at the end of sixth cycle with the $\lambda$ and $\Theta_{H}$.

The thermal analyses are also performed for $\lambda=10 \mathrm{~W} / \mathrm{m}-\mathrm{K}$ in the case of $\Theta_{H}=1$ degree, by increasing $\omega$ from 1 to 10 degrees/s to determine the effects of $\omega$ on the temperature and on the thermal stress ratio. The obtained results are presented in figure 15 and shows that the increase of $\omega$ reduces significantly (exponentially) the maximum effective thermal stress ratio (from 168 to $62^{\circ} \mathrm{C}$, approximately $63 \%$ ).

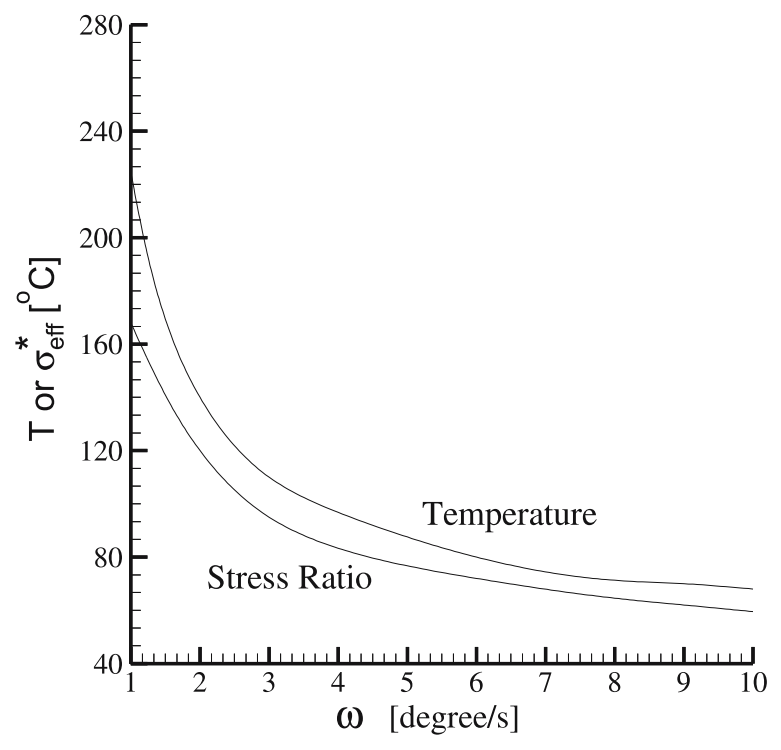

Figure 15. Variations of the maximum temperature and the maximum effective thermal stress ratio in the hollow sphere at the end of sixth cycle with $\omega$, $\left(\lambda=10 \mathrm{~W} / \mathrm{m}-\mathrm{K}, \Theta_{H}=1\right.$ degree $)$. 
These numerical results would help to determine the thermally-induced stresses, occurring in similar hollow spheres during the moving heating process, for a wide thermal conductivity spectrum of steel. For physical properties of any steel and any $q_{0}$ value, the effective stress, $\sigma_{\text {eff }}$, can be easily calculated by using eq. ( $5 \mathrm{~d}$ ). The effective thermal stresses obtained from the peaked effective thermal stress ratios in these figures may exceed the yield stress of selected steel. As already known, when the thermal stresses exceed the yield stress at the corresponding temperature, plastic deformation occurs. Furthermore, the thermally-induced stresses (especially at the segments at which they peak) may lead to micro-cracks, decrease in strength and can cause fatigue and possibly catastrophic failure. They may also remain in the structure or product as residual stresses and algebraically add to stresses developed under service and/or extreme loading conditions. Therefore, it must be considered that the thermally-induced stress arising during the process time does not exceed the yield stress of the processed steel.

\section{Conclusions}

A hollow steel sphere (workpiece) heated partly-circumferentially by a moving uniform heat source applied on its outer surface under stagnant ambient conditions is considered to analyse numerically the transient temperature and thermal stress distributions. The numerical analyses were performed in various thermal conductivities and in the different heated segment areas. The specific conclusions derived from this study can be listed briefly as follows:

(i) The temperature gradients and the thermal stress ratios peak at the heated segments because of the motion of the heat source, and however, after four-five cycles, the low peaks are noticed.

(ii) The grades of the temperature can be reduced in a considerable amount (approximately in the ratio of $1 / 2$ ) by increasing $\lambda$, from 10 to $50 \mathrm{~W} / \mathrm{m}-\mathrm{K}$.

(iii) The expansion of $\Theta_{H}$ does not much influence the temperature levels.

(iv) The maximum effective thermal stress ratio reaches $180^{\circ} \mathrm{C}$. It must be considered that the thermally-induced stress arising during the process time doest not exceed the yield stress of the processed steel.

(v) The maximum effective thermal stress ratio decreases exponentially with the increase of $\lambda$ (approximately 75\%) and with the increase of $\omega$ (approximately 63\%).

\section{Nomenclature}

$\begin{array}{ll}A & \text { area }\left[\mathrm{m}^{2}\right] \\ C_{P} & \text { specific heat }[\mathrm{J} / \mathrm{kg}-\mathrm{K}] \\ E & \text { modulus of elasticity }[\mathrm{Pa}] \\ h & \text { heat transfer coefficient }\left[\mathrm{W} / \mathrm{m}^{2}-\mathrm{K}\right] \\ j & j \text {-th cycle } \\ \text { MHS } & \text { moving heat source } \\ n & \text { total cycle number } \\ q_{0} & \text { heat flux intensity }\left[\mathrm{W} / \mathrm{m}^{2}\right] \\ q^{\prime \prime} & \text { heat flux per unit area }\left[\mathrm{W} / \mathrm{m}^{2}\right] \\ Q & \text { heat transfer rate }[\mathrm{W}] \\ P & \text { time for one cycle }[\mathrm{s}]\end{array}$




$\begin{array}{ll}r & \text { radial component }[\mathrm{m}] \\ R & \text { radius of sphere }[\mathrm{m}] \\ t & \text { time }[\mathrm{s}] \\ T & \text { temperature }\left[{ }^{\circ} \mathrm{C}\right] \\ U D F & \text { user defined function } \\ x, y & \text { Cartesian components }[\mathrm{m}]\end{array}$

\section{Greek symbols}

$\begin{array}{ll}\alpha & \text { thermal expansion coefficient }\left[1 /{ }^{\circ} \mathrm{C}\right] \\ \lambda & \text { thermal conductivity }[\mathrm{W} / \mathrm{m}-\mathrm{K}] \\ \rho & \text { density }\left[\mathrm{kg} / \mathrm{m}^{3}\right] \\ \nu & \text { Poisson's ratio } \\ \theta & \text { azimuthal component [radian] } \\ \phi & \text { zenithal component [radian] } \\ \tau & \text { normalized time }[\mathrm{s}] \\ \sigma & \text { thermal stress }[\mathrm{Pa}] \\ \sigma^{*} & \text { thermal stress ratio }\left[{ }^{\circ} \mathrm{C}\right] \\ \omega & \text { angular speed }[\text { degree } / \mathrm{s}] \\ \Theta & \text { zenithal segment }[\text { degree }]\end{array}$

\section{Subscripts}

$\begin{array}{ll}a, b & \text { starting and ending points } \\ \mathrm{amb} & \text { ambient } \\ c & \text { cold } \\ \text { eff } & \text { effective } \\ h & \text { hot } \\ H & \text { heated } \\ i & \text { inner } \\ \max & \text { maximum } \\ o & \text { outer } \\ r & \text { radial } \\ t & \text { tangential }\end{array}$

\section{References}

Al-Huniti N S, Al-Nimr M A, Naji M 2001 Dynamic response of a rod due to a moving heat source under the hyperbolic heat conduction model. J. Sound Vibrations 242(4): 629-640

Alzaharnah T, Yilbas B S, Hashmi M S 2000 Conjugate heat transfer in fully developed laminar pipe flow and thermally-induced stresses. Computer Methods in Applied Mech. and Eng. 190: 1091-104 Alzaharnah T, Yilbas B S, Hashmi M S 2001a Pulsating flow in circular pipes-The analysis of thermal stresses. Inter. J. Pressure Vessels and Piping 78: 567-79

Alzaharnah T, Hashmi M S, Yilbas B S 2001b Thermal stresses in thick-walled pipes subjected to fully developed laminar flow. J. Materials Processing Technol. 118: 50-7 
Baïri A, Alilat N, Bauzin J G, Laraqi N 2004 Three-dimensional stationary thermal behaviour of a bearing ball. Inter. J. Thermal Sci. 43: 561-568

Childs K W, Giles G E, Bryan C B, Cobb C K 1990 Heating: A computer program for multidimensional heat transfer analysis (Version 7.2), Sect. F10 of SCALE: A Modular Code System for Performing Standardized Computer Analyses for Licensing Evaluation, ORNL/NUREG/CSD-2/V2/R3, Martin Marietta Energy Systems, Inc., Oak Ridge Natl. Lab., draft February. Available from Radiation Shielding Information Center as CCC-545

Eslam M R, Babaei M H, Poultangari R 2005 Thermal and mechanical stresses in a functionally graded thick sphere. Inter. J. Pressure Vessels and Piping 82(7): 522-527

Fauple J H, Fisher F E 1981 Engineering design-A Synthesis of stress analysis and materials engineering (New York: Wiley)

Fluent Incorporated 2003 FLUENT User's guide version 6.1

Genç M S, Özışık G, Yapıcı H 2009 Numerical study on thermally-induced stress distributions in a rotating hollow disk heated from one side surface with a moving heat source. Proceedings of the IMechE Part C: J. Mechanical Eng. Sci. 223(8): 1877-1887

Kim T S, Lee D K, Ro S T 2000 Analysis of thermal stress evolution in the steam drum during start-up of a heat recovery steam generator. Applied Thermal Eng. 20: 977-92

Laraqi N, Bairi A, Segui L 2004 Temperature and thermal resistance in frictional devices. Applied Thermal Eng. 24: 2567-2581

Li J, Li J C M 2005 Temperature distribution in workpiece during scratching and grinding. Materials Sci. and Eng. A409: 108-119

Moulik P N, Yang H T Y, Chandrasekar S 2001 Simulation of thermal stresses due to grinding. Inter. J. Mech. Sci. 43: 831-851

Özışık G, Genç M S 2008 Temperature and thermal stress distribution in a plate heated from one side surface with a moving heat source (in Turkish) J. Faculty of Eng. and Agriculture of Gazi University 23(3): 601-610

Sunar M, Yilbas B S, Boran K 2006 Thermal and stress analysis of a sheet metal in welding. J. Materials Processing Technol. 172: 123-129

Yang C 2006 The determination of two moving heat sources in two-dimensional inverse heat problem. Applied Mathematical Modelling 30: 278-292

Yapıc1 H, Albayrak B 2004 Numerical solutions of conjugate heat transfer and thermal stresses in a circular pipe externally heated with non-uniform heat flux. Energy Conversion and Management 45: $927-37$

Yapıcı H, Yalçın Ş 2004 Transient temperature and thermally-induced stress distributions in a partlycircumferentially heated cylindrical workpiece. Heat Mass Transfer 41: 104-111

Yapıcı H, Bastürk G, Albayrak B 2005 Numerical study on conjugate heat transfer in laminar fully-developed flow with temperature-dependent thermal properties through an externally heated $\mathrm{SiC} / \mathrm{SiC}$ composite pipe and thermally-induced stress. Energy Conversion and Management 46: 633-654

Yapıcı H, Bastürk G 2005a Numerical solutions of transient conjugate heat transfer and thermallyinduced stress distribution in a heated and rotating hollow disk. Energy Conversion and Management 46: 61-84

Yapıcı H, Bastürk G 2005b Numerical solutions of transient temperature and thermally-induced stress distributions in a solid disk heated with radially periodic expanding and contracting ring heat flux. J. Materials Processing Technol. 159: 99-112

Yapıcı H, Bastürk G 2006 Reduction of thermally-induced stress in a solid disk heated with radially periodic expanding and contracting ring heat flux. J. Materials Processing Technol. 180/1-3: 279-290

Yapıcı H, Genç M S, Özışık G 2008 Transient temperature and thermal stress distributions in a hollow disk subjected to a moving uniform heat source. J. Thermal Stress 31: 476-493

Yilbas B S, Faisal M, Shuja S Z, Arif A F M 2002 Laser pulse heating of steel surface and flexural wave analysis. Optics and Lasers in Eng. 37: 63-83 